\title{
Exercise restores endothelial function independently of weight loss or hyperglycaemic status in $\mathrm{db} / \mathrm{db}$ mice
}

\author{
F. Moien-Afshari • S. Ghosh • S. Elmi • M. M. Rahman • \\ N. Sallam • M. Khazaei $\cdot$ T. J. Kieffer • \\ R. W. Brownsey $\cdot$ I. Laher
}

Published online: 13 November 2008

(C) Springer-Verlag 2008

Erratum to: Diabetologia (2008) 51:1327-1337

DOI 10.1007/s00125-008-0996-x

The last author regrets the omission of three authors from this paper. The correct author list is shown above.

The online version of the original article can be found at http://dx.doi. org/10.1007/s00125-008-0996-x.

F. Moien-Afshari · S. Elmi • M. M. Rahman · N. Sallam •

I. Laher $(\bowtie)$

Department of Pharmacology and Therapeutics,

Faculty of Medicine, University of British Columbia,

2176 Health Sciences Mall,

Vancouver, BC V6T 1Z3, Canada

e-mail: ilaher@interchange.ubc.ca

S. Ghosh

Department of Pediatrics, Child and Family Research Institute,

Vancouver, BC, Canada

M. Khazaei

Department of Physiology,

Isfahan University of Medical Sciences,

Isfahan, Iran

T. J. Kieffer

Departments of Cellular \& Physiological Sciences and Surgery,

University of British Columbia,

Vancouver, BC, Canada

R. W. Brownsey

Department of Biochemistry and Molecular Biology,

Faculty of Medicine, University of British Columbia,

Vancouver, BC, Canada 